\title{
Desinstitucionalização Psiquiátrica no Brasil: riscos de desresponsabilização do Estado?
}

\author{
Ellayne Karoline Bezerra da Silva \\ Universidade Federal do Piauí (UFPI)
}

\author{
Lúcia Cristina dos Santos Rosa \\ Universidade Federal do Piauí (UFPI)
}

\section{Desinstitucionalização Psiquiátrica no Brasil: riscos de desresponsabilização do Estado?}

Resumo: O artigo analisa o processo de desinstitucionalização resultante do movimento de Reforma Psiquiátrica, discutindo, em especial, o lugar destinado pelas famílias das pessoas com transtornos mentais (PCTM), a partir das alterações nas funções do Estado neste processo. Baseia-se em revisão bibliográfica. No que concerne à trajetória histórica da família brasileira e, mais especificamente, da família no contexto da saúde mental, que deslocam os papéis e lugares dos diferentes grupos familiares na direção do processo de inserção comunitária das PCTM, constatou-se que não basta fechar os manicômios ou reduzir o número de leitos psiquiátricos, se antes não forem modificados os significados desses aparatos nos cernes familiar, comunitário e social. Para que a Reforma Psiquiátrica se efetive, a família tem que ser vista como agente fundamental de transformações da percepção de loucura, bem como ser incluída de forma responsável no processo de cuidado, recebendo suporte e partilhando atribuições juntamente com o Estado e a comunidade.

Palavras-chave: Desinstitucionalização. Família. Políticas de Saúde Mental.

\section{Deinstitutionalizing Psychiatry in Brazil: Risks of Removing the State's Responsibility?}

Abstract: This study analyses the deinstitutionalization process that resulted from the Psychiatric Reform movement, discussing, in particular, the destinations indicated by families of people with mental disturbances, based on changes in the functions of the state in this process. The study is based on a bibliographic review. For better contextualization of this issue, some aspects considered relevant were mentioned. Concerning the historic trajectory of the Brazilian family, and more specifically, of the family in the context of mental health, which shifts the roles and places of the different family groups in the community insertion of people with mental disturbances, the study found that it is not enough to close asylums or reduce the number of psychiatric beds, if the meanings of the apparatus at the family, community and social levels are not first modified. Moreover, for the psychiatric reform to be effective, the family must be seen as an essential agent in the transformations of the perception of madness, and be included in a responsible manner in the process of care, receiving support and sharing attributions with the state and the community.

Keywords: Deinstitutionalization. Family. Mental health policies. 


\section{Introdução}

O movimento de Reforma Psiquiátrica, concebido como “"...] conjunto de transformações de práticas, saberes, valores culturais e sociais em torno do 'louco' e da 'loucura', mas especialmente em torno das políticas públicas para lidar com a questão" (BRASIL, 2004, p. 58), constrói um novo modelo de assistência na área de saúde mental baseado na desinstitucionalização dos manicômios, no reconhecimento da cidadania da pessoa com transtorno mental e no cuidado na comunidade. Segundo Amarante (1996), a desinstitucionalização recebeu três endereçamentos históricos nos processos reformistas ocorridos no mundo Ocidental: um deles, vinculado à experiência norte-americana do Governo Kennedy, fundamentado na psiquiatria preventiva e comunitária, redundou num processo de desospitalização, ou seja, retirada das pessoas com transtornos mentais de serviços fechados, desospitalizando-as, circunscrito a deliberações saneadoras e racionalizadoras. Outra vertente, ligada à primeira, mas intensificando-a, tem por eixo os desdobramentos de processos desospitalizadores, que resultaram em desassistência, quer dizer, a saída do Estado do processo de proteção social às pessoas com transtorno mental, refletindo no seu abandono, "seja pela premissa crítica, correta, de que seu objetivo pode ser o de reduzir ou erradicar a responsabilidade do Estado para com estas pessoas e familiares, seja por uma compreensão pouco correta do conteúdo teórico que está em jogo" (AMARANTE, 1996, p. 21). A terceira vertente, abraçada pelas lideranças do movimento reformista brasileiro, orienta a desinstitucionalização para a desconstrução de saberes, práticas e perspectivas que levem à segregação, estigma e destituição de direitos da pessoa com transtorno mental. Vincula-se à tradição italiana construída por Franco Basaglia, exigindo a presença do Estado na proteção social à pessoa com transtorno mental e a seus familiares, reconstruindo a complexidade do viver com o transtorno mental, no sentido de reinventar a vida e produzir saúde.

Rotelli et al. (1990), no entanto, chama a atenção para o fato de que a direção do processo desinstitucionalizante não está dada a priori, exigindo vigilância constante acerca de seus rumos, haja vista que propostas orientadas por setores de esquerda e progressista, mesmo na terceira perspectiva, podem ser apropriadas e redirecionadas pelo ideário neoliberal, levando à desresponsabilização do Estado com a proteção social.

As transformações que surgiram no modelo de assistência em saúde mental com a implementação da reforma psiquiátrica, também trouxeram às famílias novas atribuições e tarefas, pois o cuidado hospitalocêntrico da PCTM, em instituições fechadas e estatais, abarcava parte significativa das necessidades de sobrevivência da pessoa com transtorno mental, circunscrito aos direitos sociais, entretanto, eliminava seus direitos civis (BOBBIO, 1992).

Em suma, o movimento de Reforma Psiquiátrica possibilitou um significativo avanço na Política de Saúde Mental, sobretudo no reconhecimento dos direitos da PCTM, e no retorno destas ao âmbito familiar e da comunidade, transpondo a concepção de que o tratamento a este público deveria ser realizado somente sob o viés de internações psiquiátricas, que, na realidade, levavam os equipamentos de internação a ser transformado em lar, onde as famílias atuavam como meros visitantes, rompendo os laços com os entes e comunidade.

Diante da relevância desse novo papel das famílias nos segmentos atuais da Política de Saúde Mental, faz-se necessário discutir acerca da atuação estatal frente a estas mudanças, tendo em vista que é direcionada ao poder público dar proteção e apoio às famílias e à PCTM neste novo processo, no arcabouço da desinstitucionalização como desconstrução.

Com o avanço do ideário neoliberal, acompanhando as tendências nas demais políticas sociais, o Estado vem transferindo suas responsabilidades a organizações voluntárias e caritativas, setor privado, mercado e para a família, apostando num discurso de emancipação social e minimização de um Estado concentrador e burocrático, quando, na verdade, este mesmo Estado, agora mínimo para suprir as necessidades sociais dos que vivem exclusivamente da venda de sua força de trabalho (ANTUNES, 2003), mostra-se um Estado aliado à acumulação capitalista, como bem propõe os ideários neoliberais.

Dessa forma, longe de finalizar e responder a todos os questionamentos sobre este assunto, este trabalho traz brevemente algumas questões que merecem destaque na atual conjuntura da Política de Saúde Mental, no que se refere às novas atribuições das famílias das PCTMs e às lacunas deixadas pelo Estado, enquanto órgão formulador e executor de políticas em conjunto com a família e comunidade.

\section{Reforma psiquiátrica e o processo de desinstitucionalização}

A Política de Saúde Mental brasileira, desde a década de 1990, toma rumos distintos, tendo em vista o novo modelo de atenção à pessoa com transtorno mental, advindos com os ideais da Reforma Psiquiátrica e do SUS, além das conquistas da Luta Antimanicomial, que visam à substituição do modelo hospitalocêntrico, centrado nas internações e medicalização da enfermidade, devendo ser priorizado o sujeito em sua totalidade, 
o contexto social em que está inserido. Torna-se necessário investir nos determinantes sociais, econômicos e culturais implicados no processo saúde-doença, no sentido de melhorar a qualidade de vida e prestar uma atenção integral e intersetorial.

Dessa forma, o novo modelo de assistência às pessoas com transtorno mental ganha maior densidade com a aprovação da Lei n. 10.216, de 6 de abril de 2001, também conhecida como Lei da Reforma Psiquiátrica, que redireciona a atenção à saúde mental para uma rede de base comunitária e dispõe sobre os direitos das PCTM.

\begin{abstract}
Ela garante ser de responsabilidade do Estado o desenvolvimento da política de saúde mental, a assistência e a promoção de ações de saúde aos portadores de transtornos mentais, com a devida participação da sociedade e da família, a qual será prestada em estabelecimento de saúde mental, assim entendidas as instituições ou unidades que ofereçam assistência em saúde aos portadores de transtornos mentais. Esta preconiza que o tratamento visará, como finalidade permanente, a reinserção social do paciente em seu meio, e a internação, em qualquer de suas modalidades, só será indicada quando os recursos extra-hospitalares se mostrarem insuficientes (VELOSO; CARLOS, 2009, p. 104).
\end{abstract}

Assim, a Reforma Psiquiátrica brasileira tem como eixos: a) processo de desinstitucionalização como desconstrução dos aparatos manicomiais; b) a descentralização da atenção na internação hospitalar em manicômios para o cuidado comunitário e c) rede diversificada de Atenção à Saúde Mental, implicando a reconstituição da complexidade das necessidades sociais subjacentes à enfermidade e à intersetorialidade. Aintersetorialidade é inerente ao processo, pois é reconhecida a complexidade do cuidar na comunidade, exigindo ações integrais, visto que, comumente, ao transtorno associam-se a pobreza, o desemprego, o analfabetismo, ou seja, as vulnerabilidades sociais em geral.

O processo de desinstitucionalização caracteriza-se por implicar novos contextos de vida para as pessoas com transtorno mental, bem como para seus familiares e "pretende mobilizar como atores os sujeitos sociais envolvidos, modificar as relações de poder entre os usuários e as instituições e produzir diversas ações de saúde mental substitutivas à internação no hospital psiquiátrico" (OLIVEIRA; MARTINHAGO; MORAES, 2009, p. 33).

O paradigma da atenção psicossocial é o balizador das mudanças em curso, compreendido como sinônimo de cidadania (SARACENO, 1996), tendo três eixos estruturantes: a) o morar, ou seja, habitar conquistando territórios novos na cidade; b) o trocar identidade, multiplicando-a, combatendo e desconstruindo estigmas e mitos; e c) o produzir valores de trocas sociais, o que implica em ampliação de laços sociais, aumentando a contratualidade, a partir dos valores destacados pela sociedade, assegurando processos de geração de emprego e renda, potencializando as capacidades das pessoas com transtorno mental.

Nesse novo contexto, foi proposta a organização da Rede de Atenção à Saúde Mental, sendo esta conceituada como "uma teia que engloba todos os serviços de saúde, mecanismo que pode promover autonomia e cidadania das pessoas com transtornos mentais" (OLIVEIRA; MARTINHAGO; MORAES, 2009, p. 39).

Contribuíram para tal organização as portarias que, juntamente com a Lei n. 10.216/2001, instituíram as experiências institucionais, como os Centros de Atenção Psicossocial (CAPS), Serviços de Residências Terapêuticas (SRT); o Programa de Volta para Casa, centros de convivência e outros, além de equipamentos voltados para potencializar o cuidado comunitário e a produção de laços sociais da pessoa com transtorno mental na sociedade.

Os CAPS, atualmente regulamentados pela Portaria n. 336/GM, de 19 de fevereiro de 2002, constituem o principal equipamento do processo de reforma psiquiátrica no País. São destinados a acolher as pessoas com transtornos mentais severos e persistentes, de forma a inseri-las na vida comunitária e familiar, buscando, assim, a sua autonomia. Funcionam como porta de entrada aos serviços para ações relacionadas à saúde mental, sendo um articulador com outras redes que oferecem serviços a este público, como o Programa de Saúde da Família, Núcleos de Apoio à Saúde da Família, ambulatórios, Residências Terapêuticas, abertura de leitos em saúde mental/atenção psicossocial em hospitais gerais, entre outros.

Com a implementação do Programa Nacional de Avaliação do Sistema Hospitalar/Psiquiatria (Pnash/ Psiquiatria) e o Programa Anual de Reestruturação da Assistência Hospitalar Psiquiátrica no SUS (PRH), é dinamizada e intensificada a redução dos leitos psiquiátricos, assegurando-se a qualidade assistencial do modelo assistencial em hospital psiquiátrico ainda coexistente com os novos equipamentos comunitários e como estratégia indutora para pressionar gestores a criar serviços de base comunitária e preservadores da cidadania da PCTM.

Vale ressaltar que a Rede de Atenção à Saúde Mental não reduz as instituições substitutivas aos hospitais psiquiátricos; envolve as instituições mencionadas, incluindo também os vínculos familiares, as associações e comunidades que, de forma compartilhada, contribuem para o cuidado e reinserção das pessoas com transtorno mental no convívio social. 
Desse modo, o novo cenário da política voltada às pessoas com transtornos mentais é marcado pela transição gradual do modelo hospitalocêntrico para o modelo comunitário, fundado na atenção psicossocial, proposto pela Reforma Psiquiátrica, no qual ainda verificam-se práticas do modelo médico, herança da longa tradição manicomial presente no modo como as PCTMs foram e são tratadas, convivendo com práticas orientadas para a reabilitação psicossocial, ampliando os laços sociais das PCTMs.

\section{Considerações gerais sobre a família brasileira}

Identificada como uma das mais antigas instituições balizadoras de valores e tradicionalmente considerada base da sociedade, sobretudo no contexto brasileiro, sem contar com um Estado de bem-estar social robusto e sólido, a família brasileira tem mantido várias funções protetivas e identitárias, tendo sua caracterização singularizada em cada momento histórico, político e econômico que viveu o País. Assim, faz-se necessário esclarecer as concepções de família apresentadas durante a formação socioeconômica do Brasil, a fim de entender melhor as grandes transformações que ocorreram no âmbito desta instituição.

Para tanto, reportemo-nos inicialmente ao período colonial, no qual, conforme Rosa (2008), a estrutura familiar englobava o casal, seus filhos, outros parentes, afilhados e até mesmo os escravos. Essa família, denominada família patriarcal, era chefiada pelo homem, que exercia as funções "militares, religiosas, afetivas e empresariais" (ROSA, 2008, p. 175), sendo a referência dominante na sociedade, portanto, mais valorizada socialmente e baseada numa rígida divisão sexual do trabalho, reproduzindo as desigualdades sociais que imperavam na sociedade, principalmente àquelas recortadas pelas dimensões de classe social, gênero e etnias.

Valores desse modelo ainda sobrevivem na sociedade contemporânea brasileira, visto que ainda se observa a persistência do imaginário social dessa família, sobretudo o autoritarismo e o machismo, coexistindo com outros valores e modos de vida familiar.

Com a industrialização e a urbanização, nos anos 1950, esse cenário, aos poucos, foi se modificando: a mulher começa a exercer um papel mais ativo fora de casa, com a sua entrada no mercado de trabalho e também nas universidades. Além do mais, com a necessidade de mão-de-obra, as famílias deslocavam-se para as cidades, passando a morar em ambientes menores, propiciando uma aproximação maior entre seus entes, modificando também o tipo de união entre eles, que passa, paulatinamente, a ser centrado, sobretudo nos vínculos afetivos, tendendo a reduzir a dimensão dos fatores econômicos e políticos.

Com essa nova organização das famílias, a mulher, antes designada para o cuidado do lar e dos filhos, é reconhecida como partícipe do meio social e passa a contribuir no sustento da casa, junto com o homem, além de ter o poder decisório equiparado ao mesmo, conquistado com a Constituição de 1988 (BRASIL, 1988).

Assim, multiplicam-se os tipos de configurações familiares, denominados por Dias (2007) como famílias plurais, resultantes da multiplicidade das relações parentais, sobretudo as promovidas pela monoparentalidade, pelo divórcio e separações conjugais. Caracterizam-se por serem famílias com uma pluralidade de vínculos afetivos, marcadamente organizados por uma reconstrução de casais, em que um ou ambos já haviam se casado e levam consigo filhos de relações anteriores.

Como observado, esta multiplicidade de formas e organizações familiares exigiu mudanças conceituais, mas também jurídicas. Prova disso são as mudanças observadas no âmbito legislativo, no qual a família, por um longo período, era limitada aos laços matrimoniais, tendo em vista que as Constituições de 1943, 1946, 1947 e 1969 reconheciam apenas as famílias constituídas pelo casamento (SALES, 2010). Essas famílias eram chefiadas pelo homem, ao qual era devido à obediência dos filhos e da esposa. Reforçava a sociedade patriarcal, hierarquizada e patrimonialista.

Com o advento da Constituição de 1988, houve a ampliação legal do conceito de família, que, agora, abrange a união estável entre o homem e a mulher, a igualdade de direitos e deveres entre o casal, a família formada somente por um dos pais e seus descendentes, bem como o reconhecimento do divórcio entre os casais (BRASIL, 1988). Nesse contexto, a família passa a ser reconhecida, sendo legalizada ou não, ultrapassando a concepção tradicional da mesma, e tendo o Estado como assegurador da assistência a todos os componentes.

Mesmo com tais avanços, ainda percebe-se a persistência de discriminação quanto às novas formas familiares em vários espaços sociais, que considera a família padrão como modelo principal de família, sendo as demais consideradas, por alguns, como "desestruturadas e desordenadas".

A par de todos esses fatos é que afirmamos a necessidade de mais uma conceituação para a família contemporânea, visto que a estrutura familiar acompanha o constante processo de transformação da sociedade nos vários âmbitos: social, econômico e político, de forma a atender esta demanda. Desse modo, o conceito de família, estabelecido pela Norma Operacional Básica/Sistema Único de Assistência Social (NOB/SUAS) 2005 e adotado nesse trabalho, é o que, a nosso ver, melhor atende à necessidade colocada acima. A família é entendida como um "núcleo afetivo, vinculada por laços consanguíneos, de aliança ou afinidade, cujos vínculos 
circunscrevem obrigações recíprocas e mútuas; organizadas em torno de relações de geração e de gênero", tendo em vista que ela não se resume aos parentes de sangue, englobando pessoas do meio social em que se encontra, como amigos e vizinhos, por exemplo. E ainda enquadra-se, nesse conceito, a concepção sociológica desta categoria, sendo então o:

[...] conjunto de pessoas ligadas por laços de sangue, parentesco ou dependência que estabelecem entre si relações de solidariedade e tensão, conflito e afeto [...] e [se conforma] como uma unidade de indivíduos de sexos, idades e posições diversificadas, que vivenciam um constante jogo de poder que se cristaliza na distribuição de direitos e deveres (BRUSCHINI, 1989 apud ROSA, 2009, p. 166).

Portanto, é arena de conflitos e de afeto, em que as contradições sociais se reproduzem e podem ser alteradas, recortadas por questões de gênero, faixa etária e hierárquicas, sendo espaço de preservação da ordem social, mas também de mudanças, pois influencia e é influenciada pelo contexto histórico, sendo um grupo dinâmico que se move na história, construindo sua própria devir histórica.

\section{A família no contexto da reforma psiquiátrica}

Em se tratando das relações das famílias de pessoas com transtorno mental com a Política de Saúde Mental, observa-se que houve transformações produzidas pelas alterações no modelo assistencial em saúde mental advindas da Reforma Psiquiátrica brasileira, principalmente no que concerne às suas atribuições/funções e tarefas, embora de forma velada nos textos legais. Isso é explicado pelas novas demandas que são colocadas, de forma implícita, para a família, pelo redirecionamento do modelo assistencial, pautado no cuidado comunitário, que inverte a complexidade da clássica hierarquização do sistema de saúde, pois cuidar na comunidade geralmente exige: a) a mediação da família, que passa a ter que conviver com o preconceito, que lhe é extensível; um manejo complexo, sobretudo nos cenários (agudização) de crise psiquiátrica, haja vista que nenhuma família está preparada para cuidar de uma pessoa com transtorno mental em seu meio (MELMAN, 2001), até porque a pedagogia hospiciocêntrica/hospitalocêntrica destitui a família como possuidora de um saber e provedora de cuidado, limitando-a a ser visita (muitas vezes, inconveniente) e informante, um recurso instrumental (ROSA, 2002), isto é, desresponsabilizando-a parcialmente do cuidado direto, que é assumido integralmente por "instituições totais" (GOFFMAN, 1992); b) ter que alterar rotinas no provimento de cuidado e destinar cuidadores leigos/cuidadores familiares, em um contexto de intensas mudanças sociodemográficas do grupo familiar, que se encontra em uma circunstância de vulnerabilidades crescentes, inclusive pelo aumento da violência urbana; c) atuar na desconstrução do estigma, que, social e historicamente, acompanhou a pessoa com transtorno mental, sob a presunção da periculosidade e incapacidade.

Assim, no modelo hospitalocêntrico, a família, bem como explicita Rosa (2002, p. 144):

[...] fica restrita ao papel de identificar a loucura, encaminhar o seu portador ao asilo para os cuidados médicos, visitá-lo, bem como fornecer as informações necessárias sobre a história de sua enfermidade. Ou seja, a relação da família com o portador de transtorno mental passa a ser mediatizada por agentes médicos e por agências estatais, encarregadas da cura, da custódia e da assistência.

De acordo com Rosa (2009), esse cenário vem se modificando no interior mesmo do modelo hospitalocêntrico, desde a implantação da Portaria n. 251/GM, de 31 de janeiro de 2002, que estabelece as diretrizes e normas para a assistência hospitalar em psiquiatria, reclassifica os hospitais psiquiátricos, define e estrutura, a porta de entrada para as internações psiquiátricas na rede do SUS. Essa Portaria prevê o preparo para o retorno da pessoa com transtorno mental à residência e o consequente preparo da família quanto à orientação acerca do diagnóstico e tratamento do usuário.

Dessa forma, o novo modelo assistencial, pautado na desinstitucionalização psiquiátrica e na visão ampliada da pessoa com transtorno mental, vai além do modelo médico e da doença em si, para só então dar conta da "complexidade do novo objeto: a pessoa em suas múltiplas conexões com o social" (MELMAN, 2001, p. 60), orientando também para uma nova forma de ver e abarcar a família no tratamento e na reabilitação da PCTM. Destarte, com a Reforma Psiquiátrica, a família:

[...] ganha uma pluralidade de sentidos e dimensões, preponderantemente como: 1) um grupo que precisa de assistência e cuidados; 2) como um recurso ou lugar, como outro qualquer, mas não o único; 3) como provedora de cuidados; 4) como avaliadora dos serviços e 5) como sujeito político (ROSA, 2009, p. 162). 
No contexto dos CAPS, a família é vista como uma parceira e partícipe fundamental.

Os familiares podem participar dos CAPS, não somente incentivando o usuário a se envolver no projeto terapêutico, mas também participando diretamente das atividades do serviço, tanto interna como nos projetos de trabalho e ações comunitárias de integração social. Os familiares são considerados pelos CAPS como parceiros no tratamento (BRASIL, 2004, p. 29).

A família é considerada um sujeito cuidador, estimulador da adesão da PCTM em relação ao projeto terapêutico singular, mas também precisa de cuidados e atenção, principalmente, por ser, quase sempre, apenas um cuidador que se sobrecarrega ou é sobrecarregado do cuidado familiar, que acaba, muitas vezes, sendo sinônimo de cuidado comunitário. A família, então, não é mais tida como um sujeito extra no tratamento, e sim como parte integrante deste, como provedora e recebedora de cuidado, numa outra divisão de cuidado com o Estado. Inserida no contexto da Reforma Psiquiátrica, é responsável por mediar o seu ente familiar que tem transtorno mental com os serviços de saúde, e com os profissionais que prestam atendimento aos mesmos, bem como dar o suporte e o apoio no convívio social.

Entretanto, é relevante elencar a quão, no geral, fica vulnerável a vida dos familiares das pessoas com transtornos mentais, visto que esses compartilham com seu ente todo o sofrimento, e até mesmo pelo preconceito que ainda está presente na sociedade em relação à enfermidade. Quando uma pessoa apresenta transtorno mental, não apenas ela sofre, mas toda a família, precisando ambos de apoio e cuidado. O convívio com uma pessoa que possua algum tipo de transtorno mental, principalmente, se for prolongado ou que apresente constantes crises, pode proporcionar uma sobrecarga a alguns membros da família e desgastes de caráter emocional, físico e econômico. As dificuldades no "lidar cotidiano" constituem sempre uma demanda importante dos familiares cuidadores e a permanência da pessoa com transtorno mental na comunidade depende exatamente do potencial dos familiares cuidadores em se sentirem capazes de cuidar e também de contribuir na minimização ou desconstrução do estigma social.

Portanto, a família, comumente, é o principal elo de enfrentamento das dificuldades, no que se refere ao relacionar-se com a enfermidade, com os estigmas e com o isolamento social ao qual está propícia a pessoa com transtorno mental, reconstruindo, assim, o convívio do ente com a sociedade.

Nesse contexto, com o novo modelo assistencial, a família é reconhecida em sua complexidade, sendo protagonista e principal parceira dos serviços no provimento do cuidado à pessoa com transtorno mental, visto, desse modo, com relevância. Ela é também requisitada no modelo comunitário e construtor de cidadania da PCTM como principal elo de reconstrução de estímulos sociais e permanência nos espaços públicos das diferentes políticas públicas. Desse modo, considera-se importante a nova visão dos familiares no cuidado comunitário da pessoa com transtorno mental colocada pela Reforma Psiquiátrica, visto que o contexto atual busca a permanência, reconstrução do elo sócio-familiar, desde que seja possível. Ressalta-se que o cuidado proposto é comunitário e não familiar, exigindo a proteção social do Estado e da sociedade em geral.

\section{Desinstitucionalização psiquiátrica ou risco de desresponsabilização do Estado?}

O novo modelo de Atenção em Saúde Mental, que visa promover maior qualidade de vida às pessoas com transtornos mentais e, por conseguinte, aos seus familiares, primordialmente, no que concerne à desinstitucionalização psiquiátrica, também traz consigo alguns desafios e lacunas, sendo uma delas alvo de análise neste trabalho: a repercussão da desinstitucionalização no âmbito familiar.

Para entender a complexa discussão acerca da nova atuação das famílias das pessoas com transtornos mentais no contexto contemporâneo das Políticas Sociais e, mais precisamente, na Política de Saúde Mental, é necessário elencar algumas categorias relevantes neste aspecto.

Entende-se por política pública “[...] uma estratégia de ação pensada, planejada e avaliada, guiada por uma racionalidade coletiva, na qual tanto o Estado como a sociedade, desempenham papéis ativos" (PEREIRA, 2008, p. 96). Em outras palavras, a política pública é um conjunto de ações ou não ações coletivas direcionadas à garantia dos direitos sociais, com a intervenção estatal e envolvimento dos mais diversos atores da sociedade. Porém, é uma arena de disputas de modelos de sociedade e de gestão do Estado e, consequentemente, de modelos de política de saúde mental.

Em meados dos anos 1990, o cenário da sociedade capitalista passa por transformações econômicas, políticas e culturais, advindas principalmente pelo neoliberalismo, que atribuem ao Estado e seu crescente investimento em políticas públicas a causa da crise, iniciada nos anos 1960 e 1970. Estas transformações são refletidas diretamente na instituição denominada família, que assume, juntamente com a comunidade, responsabilidades antes direcionadas somente ao poder público via instituições totais. 
O projeto neoliberal aposta numa sociedade que, longe de ser emancipada, "mostra-se sobrecarregada com tarefas e responsabilidades que, por dever de cidadania, pertencem ao Estado" (PEREIRA, 2010, p. 32); uma sociedade pluralista de bem-estar. Na visão dos neoliberalistas, o pluralismo de bem-estar contemporâneo recomenda uma maior participação do setor privado, tanto mercantil como não mercantil, em substituição ao modelo rígido de proteção social, do qual o Estado era o principal regulador (PEREIRA, 2010).

Para os críticos, os ideários neoliberais estavam calcados na minimização do Estado enquanto órgão que promove e regula as políticas sociais, diminuindo, assim, sua responsabilidade coletiva de proteção social e transferindo esta responsabilidade para os indivíduos, em especial, às famílias, agora incluídas como essenciais na provisão do bem-estar. A família vem assumindo papel central nas políticas sociais por meio do discurso de sua valorização no contexto da vida social. Em contrapartida, vem sofrendo diante das consequências do neoliberalismo e da reestruturação produtiva que, associados, vêm provocando altos índices de desemprego, subemprego, enquanto processo de precarização do trabalho, bem como o afastamento do Estado na regulamentação e garantia de políticas públicas.

Na contemporaneidade, a família é incluída como eixo estruturante das políticas públicas de saúde e assistência social por meio do princípio da matricialidade sociofamiliar, cujo objetivo principal é "fortalecer e garantir apoio à família no exercício de seu papel de proteção e cuidados e fortalecimento da convivência familiar e comunitária" (FERREIRA; CRUS; MATIAS, 2012, p. 3). Desse modo, a família e os indivíduos devem receber apoio para exercer sua função protetiva nos seus territórios.

A matricialidade sociofamiliar representou uma conquista fundamental para as políticas, no entanto, contraditoriamente ao previsto na legislação, expõe este segmento aos efeitos desastrosos do projeto neoliberal, já que utiliza o seio familiar enquanto "agente privado de proteção social” (PEREIRA, 2010, p. 26), sem lhe conferir condições mínimas para uma boa atuação destes sujeitos.

Mioto (2010) identifica duas grandes tendências relacionadas à incorporação da família pelas políticas públicas: a familista e a protetiva. A tendência familista defende a centralidade na família, acreditando na sua capacidade de cuidado e proteção. Assim, as políticas públicas são fundamentadas na perspectiva de que as necessidades dos cidadãos devem ser supridas pelo mercado e pela família. A intervenção estatal é realizada temporariamente somente quando estes setores falham em suas atuações. Em contraposição, a tendência protetiva defende que a capacidade do cuidado e proteção da família está intimamente ligada à proteção garantida pelas políticas públicas. Assim, a tendência familista responde às falhas da atuação da família enquanto incapacidade e culpabilização desta em prover suas necessidades; e a tendência protetiva compreende que, no âmbito familiar, encontrarão dificuldades que precisam ser sanadas pelas políticas públicas.

A política de saúde mental, no contexto atual das demais políticas sociais, passa por processos de transformações resultantes, principalmente, do movimento de Reforma Psiquiátrica e do processo de desinstitucionalização, o qual busca incluir a família como principal parceira dos serviços, fortalecendo-a e apoiando-a frente ao seu papel de proteção e cuidados, bem como fortalecendo a convivência co-

A complexidade no trabalho tido pelas famílias no provimento do cuidado doméstico à PCTM, anteriormente vinculado às internações psiquiátricas e de responsabilidade estatal, atualmente retorna à família, com escasso preparo. munitária destes sujeitos. Assim, cabe à família uma grande responsabilização no que concerne ao cuidado da pessoa com transtorno mental, família esta, que, por si só, já carrega o peso do preconceito, estigma e culpabilização da sociedade em ter um ente com transtorno mental, dentre outras mazelas que acometem estes sujeitos. Além disso, está sobrecarregada pela crise socioeconômica e pelas intensas alterações sociodemográficas em seu interior, refletidas na sua dinâmica societária.

É nesse sentido que se faz necessário um questionamento acerca da responsabilidade estatal no provimento de cuidado às pessoas com transtornos mentais, diante da desinstitucionalização em saúde mental. Há aqui o reconhecimento dos avanços quanto aos serviços trazidos pela reforma, através dos Centros de Atenção Psicossocial, Residências Terapêuticas, Programa de Volta para Casa, dentre outros, embora ainda se perceba que muito tem que ser aprimorado para que, de fato, seja garantida a cidadania das PCTM e de seus familiares.

A complexidade no trabalho tido pelas famílias no provimento do cuidado doméstico à PCTM, anteriormente vinculado às internações psiquiátricas e de responsabilidade estatal, atualmente retorna à família, com escasso preparo. Esse processo exige estratégias no lidar com as implicações objetivas e subjetivas das famí- 
lias: a primeira, atrelada principalmente à sobrecarga do cuidado em um único cuidador, por exemplo; e a segunda, vinculada "às frustações, sentimentos de impotência e culpa, ou seja, com suas próprias emoções" (ROSA, 2009, p. 189).

Portanto, a Política de Saúde Mental, enquanto Política Social, não deve ter como objetivo “pressionar as pessoas para que elas assumam responsabilidades além de suas forças e de sua alçada, mas o de oferecer-lhes alternativas realistas de participação cidadã" (PEREIRA, 2010, p. 40). Logo, é relevante que o Estado, por meio de suas ações, permita uma revalorização da família, enquanto parceira dos serviços, mas que esta parceria não signifique o recuo da atuação estatal no processo de proteção da família, e sim, que atue, de forma conjunta, Estado, família e comunidade, para promover o bem-estar e a cidadania social.

\section{Considerações finais}

A Reforma Psiquiátrica marcou o percurso histórico da construção e reconhecimento da cidadania da PCTM, moldando um dos avanços fundamentais para a mudança no modelo assistencial rumo à liberdade e comunidade, os CAPS. Embora ainda estejam em processo de implantação e consolidação, tais serviços passam por várias dificuldades, por estarem muito imbricados ao antigo modelo assistencial, o hospitalocêntrico.

No contexto reformista e desinstitucionalizante, um novo olhar também é direcionado ao papel das famílias, vistas como partícipes dos serviços de saúde mental; protagonistas no cuidado à pessoa com transtorno mental, bem como sujeitos que precisam de cuidado, proteção social, diante da trajetória intensa pela qual comumente passam. A família é tida como referência principal, dentre outros, pela proximidade e por conhecer as reais necessidades do seu ente acometido pelo transtorno mental. Acredita-se que a família tem o potencial no provimento de cuidado, pois é no "ensaio e erro" que constroem estratégias no lidar cotidiano com a PCTM.

Entretanto, ainda é muito falha a atuação do Estado por meio dos serviços ofertados, frente aos novos papéis direcionados aos familiares, que se sentem, geralmente, impotentes no lidar com a situação a que são inseridos, bem como estão, muitas vezes, envoltos por outras fragilidades resultantes do surgimento do transtorno mental e pelas vulnerabilidades de seu contexto de vida e conjuntura social, por exemplo.

Aos familiares das PCTM são direcionadas novas exigências e um maior comprometimento no provimento do cuidado doméstico e "comunitário", sem que o Estado lhes ofereça suporte necessário para tanto, o que contraria os próprios princípios da Reforma Psiquiátrica, que se fundamenta no apoio e fortalecimento das famílias, pelo Estado, neste novo papel assumido por esta instituição, na forma de investimentos em educação, saúde, ampliação do protagonismo/controle social, ações de combate ao estigma comunitário, ausência que enseja o risco de desresponsabilização estatal na assistência e garantia de proteção. Esses aspectos estão intimamente influenciados pelas transformações advindas dos pressupostos neoliberais que têm se firmado no recuo da atuação do Estado na intervenção social, contribuindo significativamente para o aumento das desigualdades e o acirramento da pobreza, o que reflete diretamente na principal instituição organizativa da vida social: a família.

\section{Referências}

AMARANTE, P. O homem e a serpente: outras histórias para a loucura e a psiquiatria. Rio de Janeiro: Fiocruz, 1996.

ANTUNES, R. Adeus ao trabalho? Ensaio sobre as metamorfoses e a centralidade do mundo do trabalho. São Paulo: Cortez; Ed. da Unicamp, 2003.

BOBBIO, N. A era dos direitos. Tradução de Carlos Nelson Coutinho. Rio de Janeiro: Campus, 1992.

BRASIL. Constituição da República Federativa do Brasil de 1988. Disponível em: <http://www.planalto.gov.br/ccivil_03/constituicao/ constituicao.htm>. Acesso em: 7 fev. 2014.

. Ministério da Saúde. Secretaria de Atenção à Saúde. Lei n. 10.216, de 6 de abril de 2001. Dispõe sobre a proteção e os direitos das pessoas portadoras de transtornos mentais e redireciona o modelo assistencial em saúde mental. Disponível em: <http:// www.planalto.gov.br/ccivil_03/leis/leis_2001/110216.htm>. Acesso em: 7 fev. 2014.

. Ministério da Saúde. Secretaria de Atenção à Saúde. Portaria 336/GM, de 19 de fevereiro de 2002. <http://dtr2001.saude.gov.br/ sas/PORTARIAS/Port2002/Gm/GM-336.htm>. Acesso em: 10 fev. 2014.

Ministério da Saúde. Secretaria de Atenção à Saúde. Departamento de Ações Programáticas Estratégicas. Saúde Mental no SUS: os Centros de Atenção Psicossocial. Brasília: Ministério da Saúde, 2004.

DIAS, M. B. Manual de direito das famílias. São Paulo: Revista dos Tribunais, 2007.

FERREIRA, R. de M. C.; CRUS, J. F. da; MATIAS, M. L. Manual sobre perspectivas para o trabalho integrado com a questão do crack e outras drogas. Departamento de Gestão do SUAS/SNAS/MDS, 2012. 
GOFFMAN, E. Manicômios, prisões e conventos. São Paulo: Perspectivas, 1992.

MELMAN, J. Família e doença mental: repensando a relação entre profissionais de saúde e familiares. São Paulo: Escrituras, 2001. MIOTO, R. C. T. A família como referência nas políticas públicas: dilemas e tendências. In: TRAD, L. A. B. (Org.). Família contemporânea e saúde: significados, práticas e políticas públicas. Rio de Janeiro: Fiocruz, 2010, p. 51-66.

OLIVEIRA, W. F. de; MARTINHAGO, F.; MORAES, R. S. M. de. Entendendo o processo da reforma psiquiátrica: a construção da rede de atenção à saúde mental. Florianópolis: Abrasme; UFSC, 2009.

PEREIRA, P. A. P. Discussões conceituais sobre política social como política pública e direito de cidadania. In: BOSCHETTI, I. S. et al. (Org.). Política social no capitalismo: tendências contemporâneas. São Paulo: Cortez, 2008, p. 87-108.

. Mudanças estruturais, política social e papel da família: crítica ao pluralismo de bem-estar. In: SALES, M. A.; MATOS, M. C. de; LEAL, M. C. (Org.). Política social, família e juventude: uma questão de direitos. São Paulo: Cortez, 2010, p. $25-42$.

ROSA, L. C. dos S. Os saberes construídos sobre a família na área da saúde metal. Serviço Social \& Sociedade, n. 71, ano XXIII, Especial. São Paulo: Cortez, 2002, p. 138-161.

. Transtorno mental e o cuidado na família. São Paulo: Cortez, 2008.

. Provimento de cuidado doméstico à pessoa com transtorno mental: a questão de gênero em evidência. In: VASCONCELOS, E.

M. Abordagens psicossociais: reforma psiquiátrica e saúde mental na ótica da cultura e das lutas populares. (v. II: Perspectivas para o Serviço Social). São Paulo: Aderaldo \& Rothschild, 2009, p. 183-205.

ROTELLI, F. et al. Desinstitucionalização. São Paulo: Hucitec, 1990.

SALES, L. C. L. de. A importância do cuidado da família com o portador de transtorno mental: um estudo no CAPS II Leste de Teresina. Trabalho de Conclusão de Curso, ICF. Teresina, 2010.

SARACENO, B. Libertando identidades: da reabilitação psicossocial à cidadania possível. Rio de Janeiro: Te Corá/Instituto Franco Basaglia, 1996.

VELOSO, L. U. P.; CARLOS, K. P. T. A nova política de saúde mental no Estado do Piauí: mudanças e perspectivas. In: ROSA, L. C. dos S.; GUIMARÃES, L. D. A.; CARVALHO, M. E. B. de (Org.). Cenários de práticas em saúde mental: a atenção psicossocial no Piauí. Teresina: Ed. da UFPI, 2009, p. 98-111.

\section{Ellayne Karoline Bezerra da Silva}

layne.karoline@hotmail.com

Mestranda em Políticas Públicas pela Universidade Federal do Piauí (UFPI)

\section{Lúcia Cristina dos Santos Rosa}

luciacsrosa@gmail.com

Doutora em Sociologia pela Universidade Federal de Pernambuco (UFPE)

Doutora em Serviço Social pela Universidade Federal do Rio de Janeiro (UFRJ)

Pós-Doutoranda em Saúde Coletiva pela Universidade Estadual de Campinas (Unicamp)

Docente do Departamento de Serviço Social na UFPI

\section{UFPI}

Campus Universitário Ministro Petrônio Portella

Bairro Ininga

Teresina - Piauí - Brasil

CEP: 64049-550 